\title{
Generic entry into a regulated pharmaceutical market
}

\author{
Iván Moreno-Torres ${ }^{*}$, Jaume Puig-Junoy ${ }^{*}$, and Joan-Ramon Borrell-Arqué
}

February 2007

\begin{abstract}
The aim of this paper is to analyse empirically entry decisions by generic firms into markets with tough regulation. Generic drugs might be a key driver of competition and cost containment in pharmaceutical markets. The dynamics of reforms of patents and pricing across drug markets in Spain are useful to identify the impact of regulations on generic entry. Estimates from a count data model using a panel of 86 active ingredients during the 1999-2005 period show that the drivers of generic entry in markets with price regulations are similar to less regulated markets: generic firms entries are positively affected by the market size and time trend, and negatively affected by the number of incumbent laboratories and the number of substitutes active ingredients. We also find that contrary to what policy makers expected, the system of reference pricing restrains considerably the generic entry. Short run brand name drug price reductions are obtained by governments at the cost of long run benefits from fostering generic entry and post-patent competition into the markets.
\end{abstract}

JEL Classification: I11, L11, L65

Keywords: Entry; Generic Drugs; Pharmaceutical industry; Reference pricing

\footnotetext{
* Research Centre for Economics and Health - CRES, Department of Economics and Business, Universitat Pompeu Fabra, Barcelona, Spain.

- Research Group on Public Polices and Economic Regulation - GPRE. Departament de Política Econòmica, Universitat de Barcelona, Barcelona, Spain.

The authors benefited from support by the Spanish Ministry of Education and Science under grant SEC2003-00036, by the BBVA Foundation under the grant for social science research 2003, and by an unrestricted educational grant from the Merck Company Foundation, the philanthropic arm of Merck \& Co. Inc., Whitehouse Station, New Jersey, USA.
} 


\section{Introduction}

It has been just since January 1997 when it became possible to introduce generic drugs in Spain. Generics are certified drugs equivalent to those brand-name medicines that are allowed to enter the market when the patents of original drugs expire. Spain has a regulation that caps the price of medicines since the 1920s. Additionally, from 2000 there is also a reference pricing system in place in Spain where the payer (the National Health System) decides on the reference price for reimbursement of each drug (López-Casasnovas and Puig-Junoy, 2000).

These changes allow us to study the entry dynamics of generics in a heavily regulated market that has turned tougher. The Spanish pharmaceutical market is the seventh greatest world market and the fifth one of the European Union (IMS Health, 2006a). The National Health System mostly funds drug consumption. It is especially interesting to analyse how generic entry is affected by price regulations and reimbursement policies.

The main purpose of this paper is to show what the drivers of generic entry in regulated markets are. We are interested in analyse to what extend entry depends on the market and drug characteristics that have already highlighted the previous literature for less regulated markets, and how regulations affect the dynamics of generic entry.

We model entry decision into several active ingredients markets. We expect that entry of generic firms is increasing with the market size, that the number of entries depends on the medicine characteristics, and that price regulations that take into account the competition of the entrant generics slow downs the entry dynamics of further generics into the markets. Our hypothesis is that generics might be bearing the cost of being the reference (Puig-Junoy, 2004a).

Previous papers have studied what are the drivers of generic entry, but most of those papers have not been able to test whether price regulations had an impact on the entry dynamics. The Spanish case with on-going reforms on price regulations and patent regimes that are gradually affecting the markets for different drugs is particularly interesting to identify the effect of regulations on new generic markets.

Danzon and Chao (2000) using cross country data suggested that regulation undermines competition in off-patent markets and that the potential cost-saving from post-patent competition is not fully realized in countries with tough price regulations. Evidence from Spain might be used to test whether the underdevelopment of the generic market is in part due to price regulation.

In the European Union (EU) there are countries with mature generic markets such as the United Kingdom, where the generic market share is over the $40 \%$, and other countries with developing generic markets where this percentage is lower than the $20 \%$. Spain is in the second group: the market share for generic medicines in Spain is $14.60 \%$ in units and $7.90 \%$ in value (IMS Health, 2006b). As it is reported by 
Simoens and De Coster (2006), this seems mainly due to the existence of brandname copy products, the existing low prices for medicines in general, and the lack of incentives to prescribe and substitute generics for brand-name drugs.

This is a relevant matter for global drug markets because many countries are reforming their drug patent regimes under the TRIPS Agreement obligations: patent rights are strengthened and new generic markets are set up (Borrell 2007). Knowing more about the drivers of generic entry will be very useful for designing pharmaceutical and competition policies when drug expenditures are one of the fastest growing components of health expenditures (OECD, 2006). A balanced reform of market regulations regarding patents, prices and reimbursement policies might become a key driver of expenditure containment.

The outline of the paper is as follows. The next section reviews the literature and explains the details that make the Spanish market for drugs interesting for research purposes. The following section shows the method and the empirical model of entry that will be used. The fourth section displays the data used in the estimations. The fifth section shows the empirical results. The next section discusses the results. Finally, the last section offers some concluding remarks.

\section{The drivers of generic entry}

There are two types of studies that have analysed generic entry into pharmaceuticals markets. Some have analysed the competition effects of the generic take-up. Some others have focussed on the drivers of entry.

The main findings of these papers are the followings: (i) the number of entries depends positively on the market size (volume of sales) and on the expected profits; (iii) there are more entries in markets for drugs that treat chronic conditions; (iv) there are less entries in markets in which there are already two or more brand-name firms competing; ( $\mathrm{v}$ ) the number of entries is affected positively by the percentage of hospital sales; (vi) the number of generic incumbent firms affects negatively new entries; (vii) there are more entries in markets similar to those in which the firm has experience; (viii) there are differences in the number of entries across therapeuticclasses; and (ix) the duration of the exclusivity period of the brand-name product affects negatively generic entry.

A seminal paper is that of Caves et al. (1991) in which it is studied how brand-name drugs firms compete with the generic entrants. This paper does not analyse the dynamics of entry. By contrast, Grabowski and Vernon (1992), another early seminal paper on generics, is the first one to explicitly analyse the dynamics of entry. They find that generic entry depends on expected profits. This finding has turned to be very robust in the subsequent literature. Frank and Salkever (1997) with a reduced-form model report that the number of generic entrants depends positively 
on the market size in terms of drug sales before the patent expiration, and there is on average one new entrant for each year since patent expiration.

Bae (1997), as the papers cited above, analyses the US pharmaceutical market, but focusing only on the factors that affect the speed and the likelihood of generic entry using a duration model. This paper introduces the degree of competition measured by the number of products in a therapeutic market. He finds that entries are slower on average in markets where there are more brand-name products competing. He also finds that generic drug entry is faster on average in larger markets, and that entry is faster for drugs that mainly treat chronic diseases.

Scott Morton (1999 and 2000) investigates generic entry decisions in the US pharmaceutical market. In the first work, Scott Morton (1999) shows that firms tend to enter therapeutic markets similar to those in which firms are already established. In addition she finds that brand-name product revenues, hospital sales, and chronic conditions make entry more likely. In a second study, Scott Morton (2000) finds not only that generic entry is positively related to brand-name revenue, hospital sales, and chronic conditions, but also that the existence of two or more brand-name firms in the same market makes this market less attractive to potential entrants, that the number of substitutes in the same therapeutic-group is not affecting entry, and that brand advertising is not deterring generic entry.

Hudson (2000) is the first paper that studies the relationship between patent expiration and the introduction of generics not only in the USA but also in the UK, Germany, and Japan. He shows that generic entry and the time lag between patent expiry and generic entry are positively and negatively, respectively, related to the size of the market at the time of patent expiration.

Finally, Rudholm (2001) focuses on generic entry and is the only study that do not analyses the US pharmaceutical market but a more regulated one, the Swedish market. He uses a count data model and his main finding is that expected profits affect positively the number of entries, but that the longer the exclusivity period of the brand-name product the lower the likelihood of generic entry.

Two recent papers also address the entry issue in US. In the first one, Reiffen and Ward (2005) estimated a structural model and conclude that there is more and faster entry in the markets with larger expected profits; and that the number of firms in each market segment depends on the expected market size. In the second one, Saha et al. (2006) estimate a simultaneous equations model and find that on average the number of new generic entrants is lower the higher the number of generic incumbents that are already in the market. They also find that on average there is more entry in the largest markets in terms of sales, and that entry dynamics differs strongly across therapeutic-classes.

None of these papers has been able to analyse to what extend the dynamics of generic entry is affected by price regulations. Only Rudholm (2001) and Ekelund (2001) have attempted to estimate the impact of reference pricing on generic entry 
using data from the Swedish market. Rudholm (2001) is not able to identify with robustness what is the impact of reference pricing on generic entry, while Ekelund (2001) finds that the probability that one or more generics is launched is on average lower when a reference price system is set up. This paper however offers just some weak evidence on the effects of price regulations on the likelihood of generic entry.

Spain offers a laboratory in which to test whether regulations affect the dynamics of generic markets. Changes in reimbursement policies have affected different active ingredients at different points in time. This dynamics allow us to observe what the effects of the new regulations are. The details of the Spanish price regulations and reimbursement policies of the Spanish markets are available at Nonell and Borrell (2001), Puig-Junoy (2004b) and Costa-Font and Puig-Junoy (2005).

For the purposes of this paper, it is worth just to take into account that the NHS in Spain is funded with taxes and provides health care services with minor nonrefundable co-payments for prescribed pharmaceuticals. Also it should be borne in mind that there are three types of prescription (or ethical) drugs in Spain: original and licensee brand-name drugs, copy brand-name drugs, and generics. Spain has not granted product patent rights for products discovered before 1992. For older drugs, there is competition between original and licensee brands on one hand, and copy brands launched by firms without a licensing agreement with the pioneering firm on the other.

Additionally, it has only been since 1997 when generic versions of out-of-patent drugs can be introduced in Spain. Generics are authorised when drugs are out-ofpatent and one of the two next conditions: (i) when generics have already been authorized in a country member of the European Union in which the original drug enjoyed product patent protection; or (ii) when it has already passed ten years since the original brand-name drug was introduced in the Spanish market ("the ten-year rule").

Since December 2000, a reference pricing system was introduced. Reference pricing has gradually been extended to regulate reimbursement price for an enlarging list of active ingredients. All versions of off-patent drugs, branded and generics, are included in their respective approved group of so-called homogenous drugs (bioequivalent drugs). A group is created once there is at least one generic version of the respective active ingredient. For each group a reference price is calculated.

Until 2003, the reference price was the weighted average of the cheapest products that reach at least a market share of $20 \%$. The reference pricing was a system that established the maximum price that could be reimbursed by the NHS for any version (branded or generic) of the same drug. Whenever the price of any prescribed drug was larger than the reference price, patients could opt for the prescribed drug paying the difference.

Since 2004 the reference pricing has turned to be a system of maximum reimbursement prices. If prescriptions are filled in with brand name drugs priced 
higher than the reference price, pharmacists are mandated to substitute to the cheapest generic version. Additionally, since 2004 the reference price system has been calculated as the mean of the three cheapest daily defined doses (DDD) for each form of administration of an active ingredient.

Finally, it should be taken into account that the Spanish pharmaceutical market is heavily regulated. All drugs (branded and generics) ex-factory maximum prices are set during the process of obtaining each original drug market approval, and usually the introduction price remains as the maximum price for most of the product life (Borrell 2003). The government uses a peculiar form of cost-based price regulation for branded drugs in which manufacturing, marketing, and research costs are allocated to new drugs. Wholesalers' and retailers' mark-ups are also regulated.

\section{Theoretical framework and empirical strategy}

The seminal contributions of empirical models of entry are those of Bresnahan and Reiss (1990 and 1991). After those papers, Berry (1992) and Pakes, Ostrovsky and Berry (2004) have pushed ahead the research on empirical entry models. From these works and especially from those applied to the pharmaceutical market (Scott Morton 2000, Rudholm 2001 and Borrell 2005) we propose an empirical model of entry to be estimated using a dataset of Spanish drug markets in which generics could be launched.

We assume that potential generic entrants face some entry costs that differ across active ingredient markets. Potential entrants are symmetric in each drug market; they have the same variable profits function and the same costs of entry. In the market for the active ingredient there is imperfect competition.

Potential entrants enter a particular market if they expect to make a non-negative profit, and the entry game has two steps: in the first one, entrants decide to enter or not a specific market and, in the second one, they play the competition game and obtain their payoff. If a firm decides not to enter into the market, she has not payoff and she does not face entry costs.

Solving the model backwards the game becomes static with only one step. Potential entrants make their entry decisions simultaneously although we typically observe a sequential entry. As Reiffen and Ward (2005) pointed for the US market, timing of entries into the market is largely not under the control of firms. They do not know the date of its approval by authority with certainty or even if they will obtain the approval at all. They neither know when, or how many, other applications for that submarket will be approved.

In the Spanish case we see that there is a backlog of applications of generics that different firms would like to launch. The Spanish Medicines Agency and the Ministry of Health group and approve a large number of backlog applications to 
launch generics containing the same active ingredient at the same time. So, it is almost impossible for firms to know ex-ante what is the waiting time until their application is approved, and how many generics of other firms will be approved simultaneously.

From the previous assumptions it is derived that a firm will enter into a market until profits, including the entry cost, in each period are driven to zero, that is until

$\Pi_{i t}^{e}\left(\Delta N_{i t} \mid N_{i t-1}\right)=V_{i t}^{e}\left(\Delta N_{i t} \mid N_{i t-1}\right)-e_{i t}=0$

where subscript $t$ refers to the period, and the subscript $i$ refers to the active ingredient submarket. $N_{i t}$ is the number of incumbent firms active in the market $i$ at time $t, \Delta N_{i t}$ is the number of firms entering the market $i$ at time $t, \Pi_{i t}^{e}$ is the expected profit flow (discounted) from entering the market $i$ at time $t, V_{i t}^{e}$ is the variable profits flow (discounted) of entry into the market $i$ at time $t$, and $e_{i t}$ is the fixed cost of entry into the market $i$ at time $t$ (unobserved random component of profits at enter).

Variable profits are really uncertain because in the period $\mathrm{t}-1$ is when the firm decides to enter or not in the next period t. In that period t-1 the firm does not know how many firms will be in the market, and its expectations regarding the quantity sold and the price depend on the number of entrants. We assume that variable profits of entry are decreasing with respect to the number of simultaneous entrants:

$V_{i t}^{e}\left(\Delta N_{i t} \mid N_{i t-1}\right)>V_{i t}^{e}\left(\Delta N_{i t}+1 \mid N_{i t-1}\right)$

On the one hand, the number of entrants will reduce the expected number of units sold by each entrant. On the other hand, the price depends negatively on the number of generic firms in the market. This result has been found in prior studies such as in Frank and Salkever (1997) for the US market. Reiffen and Ward (2005), also for the US, found that, for markets of sufficient size, eight or more entries lead to near-competitive generic prices. Even in a market with regulated prices it is expected a price reduction when the number of competitors increases.

In Spain the drug maximum prices are fixed in a negotiation between the firm and the health authorities and in the case of the generic medicines it is systematically observed that new generic entrants have lower maximum regulated prices than generic incumbent firms. Then, the price at which new entrants will sell their production is expected to be decreasing on the number of generic incumbents. 
Moreover, when there are new generics in the market with lower prices and the reference price is recalculated, the new reference price is also lower.

On the other hand, $e_{i t}$ could be interpreted as the cost of entry of the zero-profit condition: when additional entrants can only earn negative profits, and thus equation (1) determines the number of firms in the market each period and is reevaluated again each period. These entry costs are supposed to depend on the market and drug characteristics and therefore, they are different in each sub-market although equal for all the potential entrants in a specific sub-market.

We also assume that firms willing to enter find that there already exist incumbent firms active in the market that do not wish to exit because continuation values are always positive,

$$
\Pi_{i t}^{c}\left(N_{i t}\right)=V_{i t}^{c}\left(N_{i t}\right)>0
$$

Where $V_{i t}^{c}$ is the variable profits flow (discounted) from continuing active in the market. Therefore, we are assuming that potential entrants are symmetric in each period but different from the incumbents and not only from the brand-name but also from the generic incumbent firms, i.e. we are assuming that there are advantages for the first generic entrants as it have been reported in the literature (Hollis 2002, Gupta et al. 2006), although in the Spanish case part of this advantage may be due to the regulation of the market.

Then, the corollary is that the number of entrants $\Delta n$ is a Nash equilibrium if and only if the random component of payoffs at the entry decision satisfies

$V_{i t}^{e}\left(\Delta n_{i t} \mid n_{i t-1}\right)>e_{i t}>V_{i t}^{e}\left(\Delta n_{i t}+1 \mid n_{i t-1}\right)$

This condition is a pure strategy Nash equilibrium because a potential entrant firm does not want to change her strategy given the other firms strategies: if there is a determined number of firms into a specific market in a specific period $\left(n_{i t}\right)$, she obtains a non-negative profit, but if there is only one more firm $\left(n_{i t}+1\right)$ she has negative profits, that is,

$$
\Pi_{i t}^{e}\left(n_{i t}\right) \geq 0>\Pi_{i t}^{e}\left(n_{i t}+1\right)
$$


If $e_{i t}$ has a density function $f(\cdot)$, then the probability that each period a number of $\Delta n$ of firms enter the market is observed as the unique Nash equilibrium outcome is

$$
\operatorname{Pr}\left(\Delta N_{i t}=\Delta n_{i t}\right)=\int_{V_{i t}^{e}\left(\Delta n_{t} \mid n_{t-1}\right)}^{V_{i t}^{e}\left(\Delta n_{t}+1 n_{t-1}\right)} f(u) d(u) \equiv P\left(\Delta n_{i t}\right)
$$

From this theoretical approach we build an empirical probability specification of a determined number of entries into each sub-market in each period. We assume a linear specification of deterministic variable profits,

$V_{i t}^{e}\left(\Delta N_{i t} \mid N_{i t-1}\right)=\mathrm{X}_{i t} \beta+\gamma N_{i t-1}+\alpha_{i}$

Therefore, the dependent variable is the number of generic firm entries into each active ingredient market each period. This variable only takes non-negative integer values and is measured in natural units on a fixed scale, and count data regression applies to dependent variables coded in this way, where the values are meaningful in themselves, in other words, where the dependent variable represents a count of events (Jones, 2005). The starting point for count data regression is the Poisson regression model, for which the mean of the dependent variable should be equal to the variance of the dependent variable conditional on the explanatory variables (equi-dispersion property).

In our case, as it is usual in empirical work, the data does not fulfil this requirement and displays over-dispersion (the mean is smaller than the variance). For that reason we use the negative binomial distribution, which is a more flexible one and relax the equi-dispersion requirement. As a result of a large proportion of zeros in the dependent variable we use also a zero-inflated negative binomial regression with fixed effects. That is, we assume that $f(\cdot)$ is a (zero inflated) negative binomial density function. This is the distribution that fits better our data and the fixed effects allow us to control for unobservable heterogeneity between active ingredients sub-markets. We then maximize a sample likelihood function to estimate the parameters of the (zero inflated) negative binomial distribution given the observed count of entries under the assumption that the conditional mean has the following specification, in which the number of entries each period depends on a matrix of market characteristics and on the number of incumbent firms active in the market,

$$
E\left(n_{i t} \mid N_{i t-1}, X_{i t}\right)=\mu_{i t}=\exp \left(\alpha_{i}+\mathbf{X}_{\mathrm{it}} \boldsymbol{\beta}+\gamma N_{i t-1}\right)
$$


where $\mathbf{X}_{\mathbf{i t}}$ is a matrix of market and drug characteristic variables, $\gamma$ and $\boldsymbol{\beta}$ are the set of parameters to be estimated and $\alpha_{i}$ are the active ingredient market fixed effects.

\section{Data}

To tackle the question on identifying the drivers of generic entry in Spain, we use an unbalanced panel with quarterly data from 1997 first quarter to 2005 second quarter. Thus, the maximum number of observed quarters for a market is 34 .

The dataset covers the largest markets of prescription drugs for which generics could potentially be launched. We analyse the oral, non-paediatric, major prescription drugs containing only one active ingredient for outpatients. Therefore, over-the-counter drugs (OTC) are not included. Neither are (i) drugs for hospital consumption (inpatient consumption); (ii) non-oral drugs; (iii) paediatric drug types; and (iv) drugs with more than one active ingredient. Finally, those active ingredient markets with a mean consumption for the analysed period lower than $€ 2$ millions per quarter are excluded.

The unit of observation is each one of the different active ingredients. Each submarket is formed by medications that compete with other brand medications that are imperfect substitutes. In the pharmaceutical industry, defining the relevant market is not an easy task because medications are indicated for treatment of different conditions. In spite of this, some authors (for example Rudholm, 2001 and 2003; Aronson et al., 2001; Bergman and Rudholm, 2003; Ekelund and Persson, 2003; and Dalen et al., 2006) usually take the therapeutic active ingredient level according to the ATC (World Health Organization Collaborating Centre for Drug Statistics Methodology Anatomical Therapeutic Classification) as an approach to the relevant market. Although it is an imperfect approach (Borrell, Costas and Nonell, 2005) 1 , it is very convenient to study competition among branded and generic versions of the same drug. We will in any case take care of the effect of therapeutic competition among different drugs.

These data are primarily derived from the prescription pharmaceutical monthly consumption of The Directorate-General of Pharmacy and Health Products of the Ministry of Health and Consumer Affairs. This information has been complemented with data from the Nomenclator Digitalis of the NHS Health Information Institute (Ministerio de Sanidad y Consumo, 2005) and from the Base de Datos del Conocimiento Sanitario 2005 -BOT PLUS- (Consejo General de Colegios Oficiales de Farmacéuticos, 2005).

\footnotetext{
${ }^{1}$ For keeping this paper short, we do not include the table that reports the 86 active ingredient markets analysed but it is available under request.
} 
Table 1 reports the definitions and the descriptive statistics of the dependent and the explanatory variables used in the next section regression analysis. As it was indicated above, the dependent variable is the flow of generic firm entries: the number of new generic firms in each active ingredient market each quarter, since generic entries are possible. We only consider as entry when we observe firm's sales for the first time. If after that moment the same firm enters into the same active ingredient market with a new drug type (for example different form, dose, etc.), it is not considered as an entry. The explanatory variables are the market and drug characteristics and the time trend. This variables are aggregated quarterly per active ingredient market and, except for the long duration dummy and the time trend, are lagged 4 quarters because firms observe the characteristics of the drug and the market long before entering into a market, and also for avoiding endogeneity problems.

\section{Table 1: Variables and descriptive statistics}

\begin{tabular}{|c|c|c|c|c|c|c|}
\hline Variable & Definition & Obs. & Mean & $\begin{array}{c}\text { Standard } \\
\text { Dev. }\end{array}$ & Min. & Max. \\
\hline Entries & $\begin{array}{c}\text { Number of generic firm } \\
\text { entries }\end{array}$ & 2135 & 0.22 & 0.69 & 0 & 13 \\
\hline Revenues & $\begin{array}{l}\text { Market revenues (in terms } \\
\text { of } € 1.000 .000 \text { ) }\end{array}$ & 2135 & 7.37 & 9.34 & 0.43 & 78.63 \\
\hline Reference price & $\begin{array}{c}\text { Dummy equal to } 1 \text { when } \\
\text { the market is regulated by } \\
\text { reference pricing }\end{array}$ & 2135 & 0.22 & 0.42 & 0 & 1 \\
\hline Generic firms & $\begin{array}{l}\text { Number of generic firms } \\
\text { in the market }\end{array}$ & 2135 & 2.53 & 4.99 & 0 & 31 \\
\hline $\begin{array}{l}\text { Active ingredients } \\
\text { per ATC-4 }\end{array}$ & $\begin{array}{l}\text { Number of active } \\
\text { ingredient in the } \\
\text { therapeutic subgroup }\end{array}$ & 2135 & 6.21 & 3.82 & 1 & 15 \\
\hline Long duration & $\begin{array}{l}\text { Dummy equal to } 1 \text { for } \\
\text { long duration treatments } \\
\text { (more than } 3 \text { months) }\end{array}$ & 2135 & 0.62 & 0.49 & 0 & 1 \\
\hline Age & $\begin{array}{l}\text { Number of quarters since } \\
\text { the first authorised drug in } \\
\text { each market }\end{array}$ & 2135 & 81.23 & 34.65 & 40 & 257 \\
\hline Trend & Time trend & 2135 & 19.14 & 9.53 & 1 & 34 \\
\hline
\end{tabular}


The variable Revenues is the market size. It is measured in terms of sales revenues and each unity corresponds to $€ 1.000 .000$. The Reference price dummy variable is equal to one when the reference price system is implemented in the market and zero otherwise. We incorporate this variable in order to evaluate the effect of the regulation through the reference price system in the number of generic firm entries. The number of Generic firms already established in the market is included to explain how the number of incumbent generic firms in the active ingredient market affects the potential generic entrant decision. The variable Active ingredients per ATC-4 is defined as the number of active ingredients in the same four-digit therapeutic subgroup (ATC), that is, the number of active ingredients that compete in the same therapeutic subgroup. This variable is the best approach to therapeutic substitution but is not perfect since the substitutability differs between active ingredients in the same therapeutic subgroup and drugs in other subgroups may also be substitutes. The dummy variable Long duration is equal to one for active ingredients indicated primarily for treatment of long duration illnesses; that is, for active ingredients intended for conditions lasting more than three months. We introduce this variable in order to analyse differences in the entry decision between active ingredient markets indicated primarily for acute and long-term treatment illnesses. Finally, the variable Age is defined as the number of quarters since the first drug authorised in each market. This variable tries to capture the age and maturity of the market.

In our dataset there are active ingredient markets in which there have been a large number of entries by 2005 as omeprazole with 34 entries, and fluoxetine, ciprofloxacin, simvastatin, enalapril and ranitidine all of them with more than 20 entries. In fact, $23 \%$ of active ingredient markets have more than 10 entries. On the other hand, 31 markets (36\% of the total analysed markets) have no generic firm entries and $77 \%$ of the markets have less than 10 entries.

Since all the markets have not been subjected to potential generic entry at the same time, we also observe differences in the dynamics of entry. Simvastatin, omeprazole, paroxetine, fluoxetine, and clarithromycin markets stand out with more than one entry per quarter, and there is more than half entry per quarter (one entry every sixmonth period) in the markets for lovastatin, ciprofloxacin, loratadine, enalapril, zolpidem, ranitidine, pravastatin, lisinopril, captorpil, alprazolam, and aciclovir. Finally, by 2005 the reference price system was not implemented in all the active ingredients markets with generics. It was implemented in 44 out of the 55 markets with at least one generic entry $(80 \%){ }^{2}$

Table 2 shows some descriptive statistics about the structure of our data sample in 2005. In the first column there are the different observed numbers of established generic firms in the 86 active ingredient markets analysed at intervals. The second column shows the number of active ingredient markets in which the number of

\footnotetext{
${ }^{2}$ For keeping this paper short, we do not include the table with entry information and reference price status for each active ingredient market but it is available under request.
} 
generic firms is repeated. We can observe that the number of markets is generally decreasing with the number of generic firms. The third and fourth columns display the number of active ingredients markets in which the reference price system has been implemented. It has been applied in 44 out of the 86 analysed markets $(51.16 \%)$ and as has been mentioned above in the $80 \%$ of markets with at least one generic firm. Finally, the last column shows the average revenue during the second quarter of 2005. This average revenue is generally increasing with the number of generic firms but not always.

Table 2: Structure of the data sample in 2005

\begin{tabular}{rlrrr}
\hline $\begin{array}{l}\text { Number of } \\
\text { generic firms }\end{array}$ & $\begin{array}{l}\text { Active ingredient } \\
\text { markets }\end{array}$ & $\begin{array}{l}\text { Markets with } \\
\text { reference pricing }\end{array}$ & $\begin{array}{l}\text { \% of markets } \\
\text { with reference } \\
\text { pricing }\end{array}$ & $\begin{array}{c}\text { Average revenue } \\
(\boldsymbol{\epsilon})\end{array}$ \\
\hline 0 & 31 & 0 & 0.00 & $4,231,324$ \\
\hline $1-5$ & 22 & 15 & 68.18 & $6,136,123$ \\
\hline $6-10$ & 15 & 11 & 73.33 & $9,002,933$ \\
\hline $11-15$ & 8 & 8 & 100.00 & $12,200,000$ \\
\hline $15-20$ & 4 & 4 & 100.00 & $5,236,320$ \\
\hline $21-25$ & 2 & 2 & 100.00 & $12,233,190$ \\
\hline $26-30$ & 3 & 3 & 100.00 & $16,300,000$ \\
\hline $31-35$ & 1 & 1 & 100.00 & $55,400,000$ \\
\hline Total & 86 & 44 & 51.16 & $12,447,232$ \\
\hline
\end{tabular}

Figure 1 shows the number of generic entries per quarter aggregated for the 86 active ingredient markets. We see a strong increasing trend in the number of entries until the first quarter of 2002 (quarter 21), when the Spanish generic market reaches 32 entries. A large number of original drug were during these years reaching the threshold of 10 years since first authorisation (the "10-year rule"). From that quarter on, there is a reduction in the number of entries until it reaches 9 entries in the fourth quarter of 2003 (quarter 28). The number of drug reaching the 10 years old threshold was not so large in this second period. Since then there is a recovery in the dynamics of generic entry. We have seen around 20 entries per quarter in the last couple of years of our sample. 
Figure 1: Generic entries per quarter (flow).

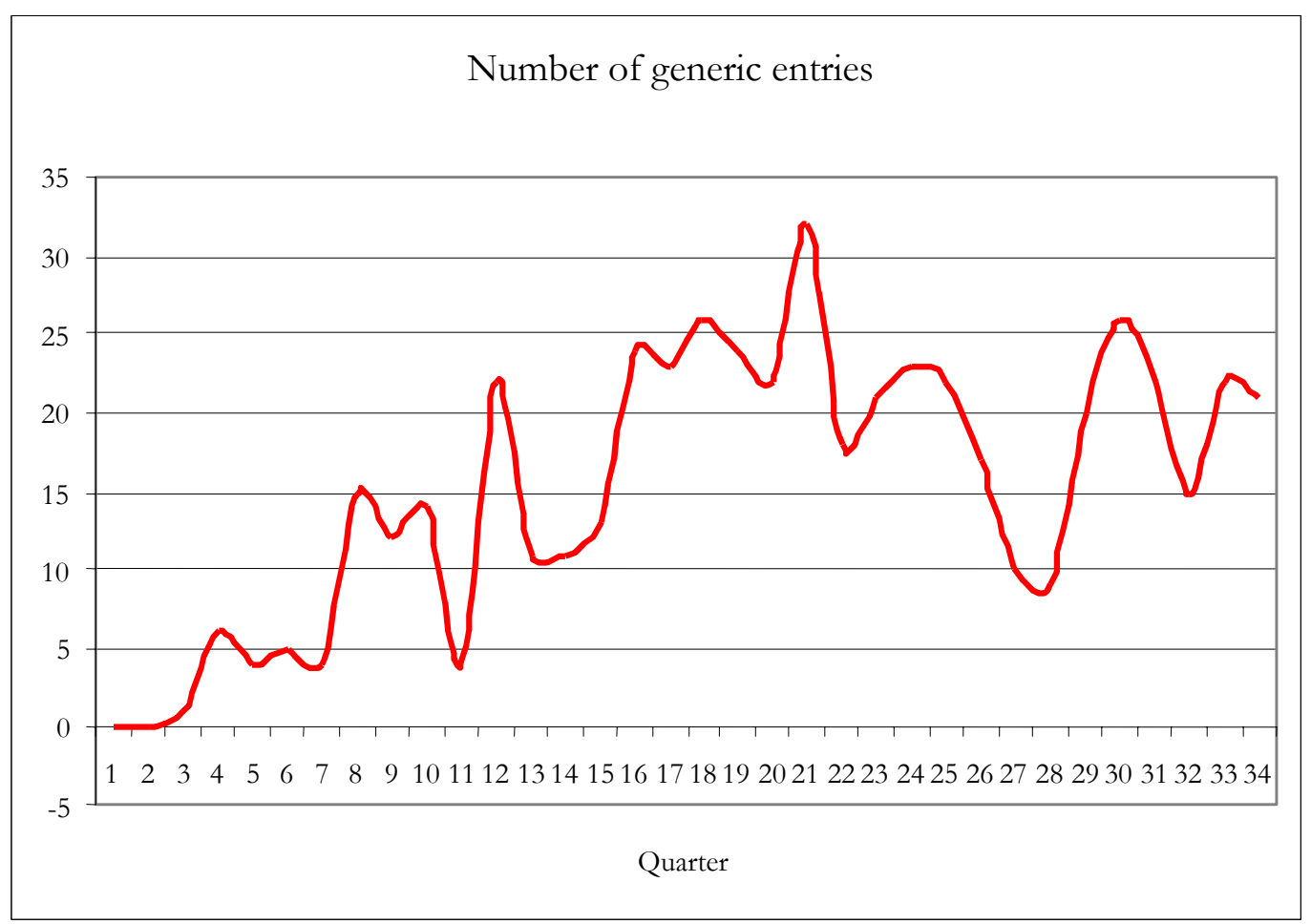

Figure 2 displays the number of generics per quarter. It shows a large increase from the first quarter, when there were only 5 different generic products, to the last quarter, when there were 503. 
Figure 2: Number of aggregated generics per quarter (stock).

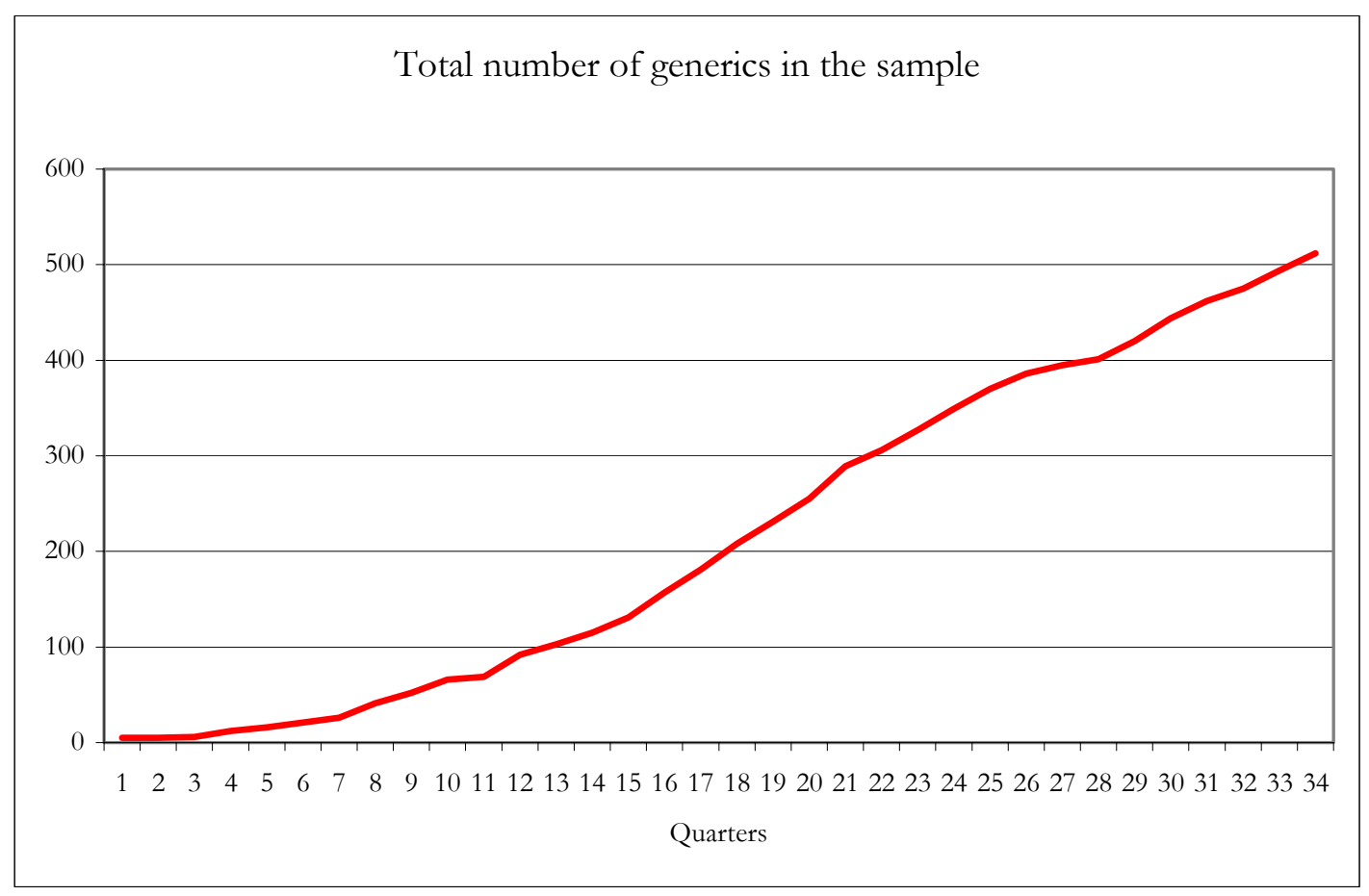

Finally, figure 3 displays the increase of the number of active ingredient markets with at least one generic firm. It goes from $2(2.33 \%)$ in the first quarter to 55 $(63.95 \%)$ in the last one. 
Figure 3: Number of active ingredient markets with at least one generic.

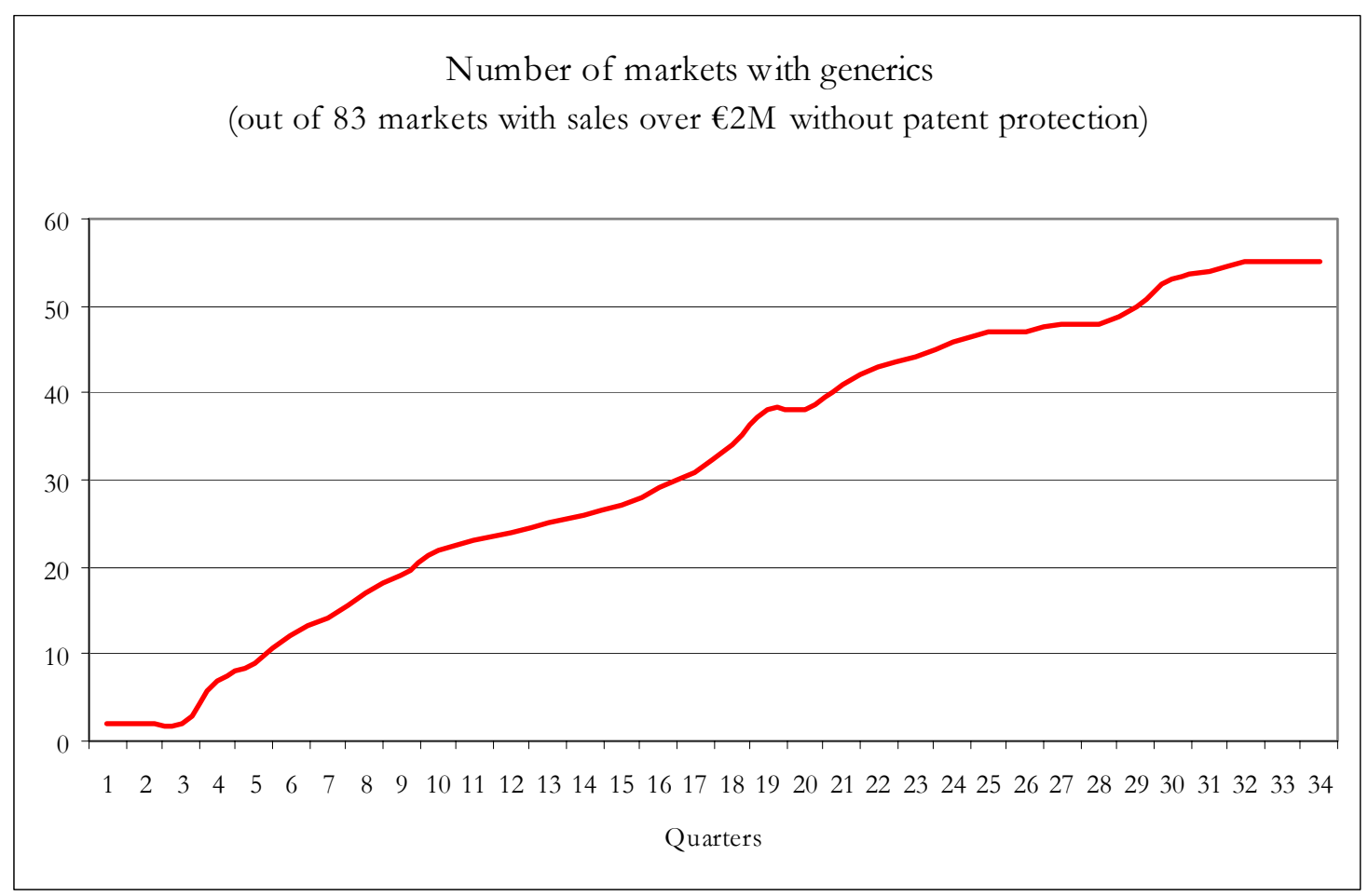

\section{Results}

Table 3 reports the maximum likelihood estimates of the model of entry. In the first column, we show the estimates of the negative binomial count panel data model. In the second column, we show the estimates of the zero-inflated negative binomial count panel data model. In both cases we control for market fixed effects 3 .

\footnotetext{
${ }^{3}$ The same specification was estimated with a Poisson and a zero-inflated Poisson count panel data model with fixed effects and the qualitative and quantitative results were similar to those obtained with the negative binomial and the zero-inflated negative binomial estimations shown in the Table 3. The likelihood ratio test recommends us to use the negative binomial distribution. These results are available under request. On the other hand, the Voung test does not provide evidence enough to opt for the zero-inflated negative binomial distribution as opposed to the non-zero-inflated version. Also, other specifications were estimated, some of them with the stock of generic firms as dependent variable. The estimations shown in the table 3 have the best properties.
} 
Table 3: Entry model estimation results

\begin{tabular}{|c|c|c|c|c|}
\hline \multirow{2}{*}{$\begin{array}{l}\text { Dependent variable: Entries } \\
\text { Explanatory variables }\end{array}$} & \multicolumn{2}{|c|}{$\begin{array}{c}\text { Negative binomial with fixed } \\
\text { effects }\end{array}$} & \multicolumn{2}{|c|}{$\begin{array}{l}\text { Zero-inflated Negative binomial } \\
\text { with fixed effects }\end{array}$} \\
\hline & Coefficients & $\begin{array}{l}\text { Mean marginal } \\
\text { effects }\end{array}$ & Coefficients & $\begin{array}{l}\text { Mean marginal } \\
\text { effects }\end{array}$ \\
\hline \multirow[t]{2}{*}{ Revenues } & $0.00043 * *$ & $0.00010^{* *}$ & $0.00040^{* *}$ & $0.00009^{* *}$ \\
\hline & $(0.0002)$ & $(0.00005)$ & $(0.00019)$ & $(0.00004)$ \\
\hline \multirow[t]{2}{*}{ Reference price } & $-0.4129 *$ & $-0.0886^{*}$ & $-0.3825^{*}$ & $-0.0820 *$ \\
\hline & $(0.2293)$ & $(0.0472)$ & $(0.2253)$ & $(0.0461)$ \\
\hline \multirow[t]{2}{*}{ Generic firms } & $-0.0834 * * *$ & $-0.0190 * * *$ & $-0.0840 * * *$ & $-0.0191 * * *$ \\
\hline & $(0.0203)$ & $(0.0050)$ & $(0.0202)$ & $(0.0048)$ \\
\hline \multirow[t]{2}{*}{ Active ingredients per ATC-4 } & $-0.8953^{* * *}$ & $-0.2042 * *$ & $-0.8516^{* *}$ & $-0.1935^{* *}$ \\
\hline & $(0.3359)$ & $(0.0789)$ & $(0.3449)$ & $(0.0794)$ \\
\hline \multirow[t]{2}{*}{ Long duration } & -0.3018 & -0.0745 & -0.7671 & -0.2229 \\
\hline & $(1.55)$ & $(0.4174)$ & $(1.5956)$ & $(0.6102)$ \\
\hline \multirow[t]{2}{*}{ Age } & 0.0048 & 0.0011 & 0 & 0.0000 \\
\hline & $(0.0082)$ & $(0.0019)$ & $(0.0085)$ & $(0.0019)$ \\
\hline \multirow[t]{2}{*}{ Trend } & $0.0425^{* *}$ & $0.0097 * *$ & $0.0476^{* *}$ & $0.0108 * *$ \\
\hline & $(0.0183)$ & $(0.0043)$ & $(0.0197)$ & $(0.0045)$ \\
\hline \multirow[t]{2}{*}{ Constant } & $-16.8514 * * *$ & & $-13.9348^{* * *}$ & \\
\hline & $(1.8744)$ & & $(1.9259)$ & \\
\hline Log pseudo likelihood & -854.7932 & & -852.1692 & \\
\hline Observations & 2135 & & 2135 & \\
\hline Active ingredients & 86 & & 86 & \\
\hline Vuong Test & & & $\begin{array}{c}1.17 \\
(0.1211)\end{array}$ & \\
\hline Likelihood ratio & & & 0.0000 & \\
\hline
\end{tabular}

Note: Heteroskedasticity robust standard errors are in brackets and ***, **, * indicates statistical significance at the $1 \%, 5 \%$, and $10 \%$ level respectively.

In both models, estimates for the coefficients of revenues, reference pricing, number of generic firms, number of active ingredients per ATC-4, and the time trend are significant. The number of generic firms already in the market reaches a significance level below $1 \%$. The number of active ingredients per therapeutic subgroup have a significance level of $1 \%$ and $5 \%$, respectively, in the negative binomial and zero-inflated negative binomial regressions. The significance level for the revenues and the time trend are 5\%. Finally, the system of reference prices has a significance level of $10 \%$. The rest of the explanatory variables do not seem to have a significant impact on the flown of generic entries. 
The signs of the estimated coefficients are the expected ones. The parameter of revenues is positive, showing that there are more entries in larger markets. The number of generic incumbent firms affects negatively the number of new entries. When there are more generic competitors, then the market turns less attractive to potential entrants. The number of active ingredients per therapeutic subgroup has also a negative effect, that is therapeutic competition also matters. A larger number of substitute active ingredients competing in the same therapeutic subgroup makes the market that belongs to this subgroup less attractive than other active ingredient markets that belong to subgroups with less substitutes. The result that the time trend has a positive coefficient could be due to the fact that before to 1997 there were not generic drugs in Spain and since then, because the markets have fulfilled progressively the legal requirements (the "10-year rule"), there has been a take-off in the number of generic firms entering the market. And finally, the reference price dummy variable has a negative coefficient. It seems that the system of reference pricing affects negatively the entry of generic firms. If potential entrants anticipate long before entry that reference prices will be imposed in those markets in which there is on average a relatively large number of generics, our estimate would show a not strong enough negative effect of reference prices due to the remaining endogeneity bias.

The estimated coefficients can be directly interpreted in qualitative terms but not in quantitative terms. For that reason, in Table 3 we also show the mean marginal effects. These have been calculated as how the expected value of the dependent variable changes when there is a partial variation in the case of continuous explanatory variables, and when there is a discrete variation from 0 to 1 in the dummies.

Thus, an increase of $€ 1.000,000$ in the quarterly market revenue increases the number of expected quarterly entries between 0.010 and 0.009 . Therefore, an increase of $€ 1.000,000$ in the quarterly market revenue raises the mean number of generic firm entries from 0.2169 to between 0.2179 and 0.2178 . If there is an increase of a standard error in the quarterly market revenue $(€ 9,336,922)$, the number of entries increases form 0.2169 to between 0.3009 and 0.3103 .

If the market moves from a situation without reference price system to another with this system, the number of expected entries is reduced between 0.08 and 0.09 . Therefore, the mean number of generic firm entries is reduced from 0.2169 to a value between 0.1269 and 0.1369 . This would be a conservative estimation of the downward effect on entry if our estimates do not correct completely the potential endogeneity bias in the parameter of the reference pricing variable.

If the number of generic incumbent firms increases in one, the quantity of entries in the next period is reduced in 0.02 and the mean number of entries changes form 0.2169 to 0.1969 . When the number of generic incumbent firms increases in one standard error ( 5 generic incumbent firms) the mean number of entries goes up by 0.1169 . 
If there is an additional active ingredient competing in the same therapeutic subgroup, there is a reduction in the number of entries between 0.19 and 0.20 . Therefore, the mean of entries goes from 0.2169 to a value in between 0.0169 and 0.0269. For an increase equal to a standard error (3.83 active ingredients), the reduction is in between 0.73 and 0.77 . This result means that for markets with few entries (a mean of quarterly entries lower than 0.75 , approximately) a standard error increase in the number of active ingredients in the subgroup implies no more entries.

Finally, the trend mean marginal effect indicates that each quarter there is an increase in the mean number of entries of $1 \%$.

\section{Discussion}

Our estimates show that the main drivers of generic entry in usual markets are also the key drivers of entry in a tough regulated market as such the Spanish one: market revenues, the number of incumbent generic firms, substitutes active ingredients, and so on. In general the coefficients signs and significances are coincident with those obtained in the prior literature.

However, some of our estimates differ from the previous literature. Scott Morton (2000) did not find that the number of substitutes within the therapeutic subgroup is a determinant of entry, although her variable definition differs from our variable, Active ingredients per ATC-4. In fact, in our work, the larger the number of active ingredients per ATC-4 the smaller the number of generic firm entries is. This effect explains, in part, why there are some active ingredient markets without generic entries (31 out of 86 , the $36 \%$ ) or only with a few entries (for $23 \%$ sub-markets there are less than 10 entries). It also highlights the relevance of competition not only in the active ingredient markets, but also within therapeutic subgroups. In Spain there are more active ingredients marketed than in other countries such as U.K., as pointed out by Borrell, Costas, and Nonell, 2005.

Another difference of our results in comparison to those found previously in the literature is the variable long-term treatment (i.e. dummy for drugs used in long term treatments) is not significant. In relation to this result, Bae (1997) found faster generic firm entries in markets of active ingredients mainly used to chronic diseases. Scott Morton (1999 and 2000) also concludes that this variable affects positively the number of generic entries.

In our case the variable age is neither significant. It was expected to have a negative effect on entries because mature markets and markets in which the brand-name products have been sold exclusively for a long time seem are less attractive for generic entry. Rudholm (2001) includes the number of quarters in which the brandname drug was sold under patent protection in his estimations and finds that it is a significant variable (5\% significance) that affects negatively the number of generic 
entries. This result might be related to the relatively less strict exclusivity enjoyed by branded products under the patent regime in force for old products.

At last, we have a positive trend coefficient; however Rudholm (2001) does not find a significant one. As it was exposed in the section above this result could be due to that the analysis is focused in the first years in which it was possible to introduce generic drugs in the Spanish pharmaceutical market and the different active ingredient markets studied were fulfilled the legal requirements to generic enter progressively, whereas in Rudholm (2001) it is analysed a longer period of time, not just the introduction of generic drugs in the pharmaceutical market.

In relation to the impact of the reference price system, it seems to constrain generic entry. This result was not expected by policy makers because the reference price system was supposed to foster generics take-off. This finding highlights that the main advantage of generic drugs respect to brand-name drugs is their lower price. By contrast, brand-name drugs have the advantage to be known by physicians as much as by patients, both have previous experience prescribing and consuming them, and firms have built-up brand image by informing doctors and patients about the clinical properties of their brand. In Spain it is observed that when the reference price system is implemented in any active ingredient market, brand-name peg down their prices very close to that reference price that becomes the cap for reimbursement purposes within the NHS. This brand-name firm strategy causes generic drugs to lose their main advantage. Generic drug prices become very similar to brand drug prices (Puig-Junoy, 2004a, 2004b, and 2005; Merino-Castelló, 2003).

Rudholm (2001) also includes a reference price system dummy to evaluate its effect on the generic entry. He finds that this variable has not effect on the generic entry in the Swedish market although, as the own author indicates, this result can be due to the fact that this variable groups the reference pricing implementation together with other reforms that made easier the registration of new generic drugs. These two reforms affect generic entry in opposite ways, probably cancelling each other in the estimation. Also for the Swedish market, Ekelund (2001) finds that the reference price system reduced the likelihood of generic entry. This author estimated a logit model, but the paper cannot identify the impact of reference pricing on the number and dynamics of entry.

We have restricted our analysis to those active ingredient markets with a mean consumption for the analysed period larger than $€ 2$ millions per quarter. This implies that small markets have not been included in the analysis. This fact could bias downwards the estimated coefficient of the variable revenues (i.e. market size) and could increase its standard error making it significant only at the 5\% level. The impact of market size on entry may be underestimated.

The specifications of the estimated models do not include some variables that were not statistically significant due to multicolineality problems. In any case, the main results offered previously are robust to including other variables that turned out to 
be statistically not significant. Additionally, our specification does not include any variable to control for incumbent strategic behaviour such as entry-deterring strategies by brand-name or generic firms. For example brand-name firms have incentives (1) to introduce their own "generics" (Mestre-Ferrándiz, 1999; Hollis, 2005), (2) to create product line extensions (Hong et al., 2005), (3) to over-invest in advertising to deter generic entry (Königbauer, 2006), etc. Assessing the impact of strategic behaviour of incumbents is open for future research.

\section{Conclusion}

The evidence from drug markets subject to tough price regulations such as the ones in Spain shows that the drivers of generic entry are similar to that of other more market friendly environments. By contrast, the evidence also shows that price regulation constrains the take-off of generic markets, and that it may constrain also competition for post-patent drugs.

Four drivers are the key for fostering generic entry. The first one is the number of generic incumbent firms. When the number of generic firms already in the market increases, there are more direct competitors and the average number of generic entries turns lower. The second driver is the number of active ingredients per therapeutic subgroup that decreases the average number of generic entries. The magnitude of this therapeutic competition effect is large. It explains, in part, why there are active ingredient markets without generics or only with few ones. The third driver of entry is market size in terms of revenues, which affects positively. If the rest of variables are constant, an increase in market revenues drives average number of generic entries up. Finally, the time trend has significant fostering effect on generic entry. It shows that until 1997 generics could not be launched in Spain, and that many active ingredients markets have been gradually open to generic firms by regulation as the original drug turn 10 years old.

Some policy implications can be derived from these results. The first one is that the main problem to foster competition through the introduction of generic drugs is market size. In small markets, there is a small probability of having enough entrants and to drive prices down to levels close to marginal costs. In these markets, policies should focus on avoiding the abuse of market power by incumbents.

By contrast, there are no competition problems in large enough markets where some generic firms enter or when there are enough competing active ingredients within the therapeutic subgroup. In those markets, more entry adds not so much competition to that already in the market, whether at the generic and therapeutic level.

In large markets, there is not need to implement the reference price system in order to achieve generic entries. It might even have adverse effects because it deters further generic entry. It deprives the main advantage of generic drugs: a lower price 
with respect to brand-name equivalents. Implementing reference pricing when there are still few generics in the market could become a policy of short run gain at a long run loss for the third party payer (the government in most cases). Reference pricing encourages brand-name drugs to peg their prices to the reference one and make further entries of generics difficult as the market for generics squeezes. Generic take-off is constrained when price regulation gets tougher, and generics bear the cost of becoming the reference price. Competition generated by generic firms would be more effective than the reference pricing to obtain prices reductions and pharmaceutical public expenditure savings in the long run, but this is a matter that requires future research for the Spanish market.

As Danzon and Chao (2000) highlighted, regulation undermines competition in offpatent markets. The potential budgetary savings from post-patent competition are not fully realized in countries with heavy regulation. According to the evidence gathered in this paper, it would be more sensible to let enough generic firms to enter drug markets before implementing mechanisms to reimburse only for the lowest price that competition has revealed. Without having enough entrants in the market, there would be not enough competition to reveal to what extend cost may be contained for third party payers.

\section{Acknowledgments}

The authors would like to thank participants at the XXVI Jornadas de Economía de la Salud in Toledo, Spain, and Pascual Segura, Lluís Segú, Marc Sáez, Ángel López, and Tomás del Barrio for helpful comments. Financial support is acknowledged from the Spanish Ministry of Education and Science under grant SEC2003-00036 and BBVA Foundation. The authors also benefited from support by an unrestricted educational grant from the Merck Company Foundation, the philanthropic arm of Merck \& Co. Inc., Whitehouse Station, New Jersey, USA. 


\section{References}

[1] Aronsson T, Bergman M, Rudholm N. The Impact of Generic Drug Competition on Brand Name Market Shares-Evidence from Micro Data. Rev Ind Organ 2001; 19: 425-435.

[2] Bae JP. Drug patent expirations and the speed of generic entry. Health Serv Res 1997; 32: 187-201.

[3] Bergman M, Rudholm N. The Relative Importance of Actual and Potential Competition: Empirical Evidence from the Pharmaceuticals Market. J Ind Econ 2003; 51: 455-467.

[4] Berry ST. Estimation of a model of entry in the airline industry. Econometrica 1992; 60: 889-917.

[5] Borrell JR, Costas A, Nonell R. Regulation and Competition in the Market for Pharmaceuticals. In The Public Financing of Pharmaceuticals: An Economic Approach, Puig-Junoy J (ed). Edward Elwar: Cheltenham and Northampton, 2005; 59-83.

[6] Borrell JR. Pricing and Patents of HIV/AIDS Drugs in Developing Countries. Appl Econ 2007; forthcoming.

[7] Borrell JR. Patents and the Faster Introduction of New Drugs in Developing Countries. Appl Econ Letters 2005; 12: 379-382.

[8] Borrell JR. Drug Price Differentials Caused by Formularies and PriceCaps. Int J Econ Bus 2003; 10: 37-50.

[9] Bresnahan T, Reiss P. Entry in Monopoly Markets. Rev Econ Stud 1990; 57: 531-553.

[10] Bresnahan T, Reiss P. Entry and Competition in Concentrated Markets. $J$ Polit Economy 1991; 91: 977-1009.

[11] Caves RE, Whinston MD, Hurwitz MA. Patent expiration, entry and competition in the US pharmaceutical industry. Brookings Pap Econ Act: Microeconomics 1991; 1991: 1-48.

[12] Consejo General de Colegios Oficiales de Farmacéuticos. Bot Plus: Base de datos del conocimiento sanitario. Consejo General de Colegios Oficiales de Farmacéuticos: Madrid, 2005.

[13] Costa-Font J, Puig-Junoy J. The pharmaceutical market regulation in Spain: is drug cost-containment under question? Journal of Pharmaceuticals Finance, Economics and Policy 2005; 13: 33-49. 
[14] Dalen DM, Strøm S, Haabeth T. Price regulation and generic competition in the pharmaceutical market. Eur J Health Econ 2006; 7: 155-220.

[15] Danzon PM, Chao WL. Does regulation drive out competition in pharmaceutical markets? J Law Econ 2000; XLIII: 311-357.

[16] Ekelund M. Generic entry before and after the introduction of reference prices. In Competition and innovation in the Swedish pharmaceutical market, Ekelund M. Stockholm School of Economics: Stockholm, 2001; chapter 4: 1-17.

[17] Ekelund M, Persson B. Pharmaceutical Pricing In A Regulated Market. Rev Econ Statist 2003; 85: 298-306.

[18] Frank RG, Salkever DS. Generic entry and the pricing of pharmaceuticals. J Econ Manage Strategy 1997; 6: 75-90.

[19] Grabowski HG, Vernon JM. Brand loyalty, entry, and price competition in pharmaceuticals after the 1984 drug act. J Law Econ 1992; 35: 331-350.

[20] Hollis A. The Importance of Being First: Evidence from Canadian Generic Pharmaceuticals. Health Econ 2002; 11: 723-734. DOI:10.1002/hec.698.

[21] Hollis A. How do Brands' "Own Generics" Affect pharmaceutical Prices? Rev Ind Organ 2005 27: 329-350.

[22] Hong SH, Shepherd MD, Scoones D, Wan TTH. Product-Line Extensions and Pricing Strategies of Brand-Name Drugs Facing Patent Expiration. J Manag Care Pharm 2005; 11: 746-754.

[23] Hudson J. Generic Take-up in the Pharmaceutical Market Following Patent Expiry: A Multi-Country Study. Int Rev Law Econ 2000; 24: 103112.

[24] IMS Health. IMS Retail drug monitor: tracking 13 key global pharma markets. IMS Health: London, 2006a.

[25] IMS Health. Estudio del impacto de los medicamentos genéricos en el mercado español. IMS Health: Madrid, 2006b.

[26] Jones AM. Applied Econometrics for Health Economists. A Practical Guide. 2nd Edition. Office of Health Economics: London, 2005.

[27] Königbauer I. Advertising and generic market entry. J Health Econ 2006; in press. doi:10.1016/j.jhealeco.2006.08.008. 
[28] López-Casasnovas G, Puig-Junoy J. Review of the literature on reference pricing. Health Policy 2000; 54: 87-123.

[29] Mestre-Ferrándiz J. The impact of generic goods in the pharmaceutical industry. Health Econ 1999; 8: 599-612.

[30] Ministerio de Sanidad y Consumo. Nomenclator Digitalis. Instituto de Información Sanitaria del Sistema Nacional de Salud, Ministerio de Sanidad y Consumo: Madrid, 2005.

[31] Nonell R, Borrell JR. Public Demand for Medicines, Price Regulation and Government-Industry Relationship in Spain. Environ Planning C: Govt Pol 2001; 19: 119-134.

[32] OECD. OECD Health Data 2006: Statistics and indicators for 30 countries. OECD: Paris, 2006.

[33] Pakes A, Ostrovsky M, Berry S. Simple estimators for the parameters of discrete dynamic games (with entry/exit examples). NBER Working Paper 10506. NBER: Cambridge, 2004.

[34] Puig-Junoy J. Los medicamentos genéricos pagan el precio de ser referencia. Revista de Administración Sanitaria 2004a; 2: 35-59.

[35] Puig-Junoy J. Incentives and pharmaceutical reimbursement reforms in Spain. Health Policy 2004b; 67: 149-165.

[36] Reiffen D, Ward ME. Generic Drug Industry Dynamics. Rev Econ Statist 2005; 87: 37-49.

[37] Rudholm N. Entry and the Number of Firms in the Swedish Pharmaceuticals Market. Rev Ind Organ 2001; 19: 351-364.

[38] Rudholm N. Competition and substitutability in the Swedish pharmaceuticals market. Appl Econ 2003; 35: 1609-1617.

[39] Saha A, Grabowski H, Birnbaum H, Greenberg P. Generic Competition in the US Pharmaceutical Industry. Int J Econ Bus 2006; 13: 15-38.

[40] Scott Morton F. Entry Decisions in the Generic Pharmaceutical Industry. RAND J Econ 1999; 30: 421-440.

[41] Scott Morton F. Barriers to Entry, Brand Advertising, and Generic Entry in the U.S. Pharmaceutical Industry. Int J Ind Organ 2000; 18: 1085-1104.

[42] Simoens S, De Coster S. Sustaining generic medicines markets in Europe. Journal of Generic Medicines 2006; 3: 257-268. 